\title{
Evaluación de Conservantes en Salchichas Tipo Vienesas Contenidas en Tripa de Celulosa
}

\author{
Geovani Trujillo Játiva, Ing. \\ Investigador, Escuela Superior Politécnica de Chimborazo \\ (ESPOCH), Ecuador \\ Vinicio Paredes Peralta, $\mathrm{MsC}$ \\ Fredy Erazo Rodríguez, $\mathrm{MsC}$ \\ Tatiana Sánchez Herrera, MsC \\ Iván Flores Mancheno, PhD
}

Docente de Tiempo Completo de la Facultad de Ciencias Pecuarias Escuela Superior Politécnica de Chimborazo (ESPOCH), Ecuador

Doi: 10.19044/esj.2019.v15n9p427～URL:http://dx.doi.org/10.19044/esj.2019.v15n9p427

\section{Resumen}

Durante la elaboración de este trabajo se elaboraron y evaluaron salchichas con tripa de celulosa aplicando tres distintos tipos de conservantes (Natamicina 0,001 g/L de agua, Sorbato de Potasio 0,6 g/L de agua, Propianato de Sodio 3,2 g/L de agua) mediante atomización, empleados como bactericidas y fungicidas: Esto se realizó con el fin de que fueran comparados con un testigo sin la aplicación de ningún conservante, por lo que se contó con cuatro tratamientos experimentales y tres repeticiones. El tamaño de la unidad experimental (T.U.E) fue de tres kilogramos de salchicha con tripa de celulosa por cada tratamiento, para lo cual se realizaron análisis microbiológicos de bacterias ácido lácticas, mohos y levaduras), y análisis organolépticos de apariencia, color, sabor y textura con 20 jueces semi entrenados, a los 15, 30 y 45 días, obteniendo los siguientes resultados: el mejor conservante, en base al tiempo de vida útil del producto,fue la Natamicina que presentó una media de 183,33 UFC/g de bacterias acido lácticas y de 0,0 UFC/g de mohos y levaduras, encontrándose dentro de los límites permitidos reportados que son $10^{7}$ para Bacterias ácido lácticas y $1,3 \times 10^{2}$ para mohos y levaduras. Dichos resultados fueron analizados mediante la prueba estadística ADEVA, con separación de medias mediante la prueba de Tukey, al 0,05\% de significancia. En cuanto al análisis organoléptico, no se encontraron diferencias significativas para ninguno de los tratamientos con valores superiores a 4 de aceptación en cada parámetro evaluado, dados por la prueba estadística de Kruskal Wallis. 
Palabras claves: Natamicina, Sorbato de Potasio, Propianato de Sodio, Tripa de celulosa

\title{
Evaluation of Preservatives in Viennese Type Sausages Contained in Cellulose Casings
}

Geovani Trujillo Játiva, Ing. Investigador, Escuela Superior Politécnica de Chimborazo

(ESPOCH), Ecuador

Vinicio Paredes Peralta, $\mathrm{MsC}$

Fredy Erazo Rodríguez, $M s C$

Tatiana Sánchez Herrera, MsC

Iván Flores Mancheno, PhD

Docente de Tiempo Completo de la Facultad de Ciencias Pecuarias Escuela Superior Politécnica de Chimborazo (ESPOCH), Ecuador

\begin{abstract}
During the elaboration of this work, sausages with cellulose casings were elaborated and evaluated by applying three different types of preservatives (Natamycin $0.001 \mathrm{~g} / \mathrm{L}$ of water, Potassium Sorbate $0.6 \mathrm{~g} / \mathrm{L}$ of water, Sodium Propanate $3.2 \mathrm{~g} / \mathrm{L}$ of water) by atomization. It is used as bactericides and fungicides. This was done in order to make a comparison with a control without the application of any preservative. So, there were four experimental treatments and three repetitions. The size of the experimental unit (TUE) was $3 \mathrm{~kg}$ of sausage with cellulose casings for each treatment, for which microbiological analysis of lactic acid bacteria, molds, and yeasts were made. Organoleptic analysis of appearance, color, taste, and texture with 20 semi-trained judges, at 15,30 and 45 days, obtained the following results. The best preservative, based on the shelf life of the product, was Natamycin, which presented an average of $183.33 \mathrm{CFU} / \mathrm{g}$ of lactic acid bacteria and $0.0 \mathrm{CFU} /$ $\mathrm{g}$ of molds and yeasts. Within the permitted limits reported, they are 107 for lactic acid bacteria and $1.3 \times 102$ for molds and yeasts. These results were analyzed by the ADEVA statistical test, with separation of means by the Tukey test at $0.05 \%$ significance level. Regarding the organoleptic analysis, no significant differences were found for any of the treatments with values higher than 4 of the acceptance in each evaluated parameter given by the statistical test of Kruskal Wallis.
\end{abstract}


Keywords: Natamycin, Potassium Sorbate, Sodium Propanate, Cellulose casings

\section{Introduction}

La elaboración de derivados cárnicos supone una oportunidad para añadir valor, reducir los precios, fomentar la inocuidad alimentaria y ampliar la vida útil. Esto a su vez puede generar un aumento de los ingresos del hogar y una mejora de la nutrición (FAO, 2014).

Los embutidos cárnicos se elaboran a partir de matrices proteicas coloidales complejas, en las cuales la procedencia y las propiedades de las proteínas utilizadas definen las características funcionales de los productos finales (Hleap, Burbano, \& Mora, 2017). Por su parte (Vargas, López , \& Flores, 2014) afirman que los embutidos son productos cárnicos elaborados con carne, sangre o una mezcla de ambas que, además de contener esencias y hierbas, contiene aditivos que son sustancias no consumidas normalmente como alimento y que se incorporan al mismo con un fin tecnológico u organoléptico.

Sabiendo que los embutidos cocidos son un grupo importante entre los productos cárnicos, en general, su elaboración implica el uso de uno o varios métodos de conservación. Mediante los procedimientos de elaboración de embutidos las materias primas adquieren mejor sabor, se ofrecen al consumidor en muy diversas formas y pueden destinarse a la alimentación humana tanto a corto como a mediano plazo.

En la clasificación general de embutidos, se encuentran los escaldados; entre los cuales se encuentra la salchicha vienesa. La salchicha vienesa es es un embutido que se elabora con carne y otros tejidos animales comestibles, curados o no, condimentados, cocidos o no, ahumados y desecados o no, que tiene como envoltura intestino delgado, esófago, vejiga, peritoneo u otras membranas animales comestibles, así como envolturas artificiales de uso permitido. También se puede definir a la salchicha como un producto blanco elaborado a base de una masa preparada con carne seleccionada, tocino perfectamente cortado, picado y mezclado, embutido en tripas finas de cerdos jóvenes, de ovinos y caprinos, o en envolturas ratifícales de uso permitido, cocido y ligeramente ahumado (Quezada, 2015).

Desde luego, los embutidos son alimentos muy perecederos debido a su elevado contenido acuoso y al valor de $\mathrm{su} \mathrm{pH}$, dos factores que favorecen el desarrollo de los posibles microorganismos contaminantes, y cuando los microorganismos alterantes se desarrollan por encima de cierto nivel, suelen dar lugar a la formación de ciertos metabolitos que provocan la descomposición del alimento. Esta alteración implica cambios organolépticos detectables al traducirse en defectos del color, modificaciones de la textura y, 
sobre todo, la aparición de olores extraños que hacen al producto no deseable, o incluso rechazable (Gil, A. et al., 2010).

Para la detección de estas alteraciones se aplican de igual forma métodos objetivos como el recuento microbiológico. cuyo resultado alcanza el valor de $10^{7}$ unidades formadoras de colonias (UFC) $/ \mathrm{cm}^{2}$ en caso de presentarse dichas alteraciones.

La proliferación de los microorganismos, nocivos o alterantes, está condicionada por los valores alcanzados por diversos parámetros relacionados con el medio ambiente: cantidad de oxígeno, temperatura, actividad de agua, etc. En vista de que la multiplicación de los gérmenes suele ser importante a temperaturas entre 4 a $20{ }^{\circ} \mathrm{C}$, se puede mejorar la conservación de los embutidos acudiendo a la protección del frío. Por ello, se puede prolongar su vida útil mediante un almacenamiento en refrigeración, teniendo en cuenta que la temperatura del almacenamiento suele ser determinante del tipo y la velocidad del desarrollo microbiano (Gil, A. et al., 2010).

Tomando en cuenta lo expuesto anteriormente, el propósito general de la presente investigación consite en realizar una evaluación de conservantes en salchichas tipo Vienesas contenidas en tripa de celulosa, propósito para el cual se plantearon los siguientes los objetivos:

- Utilizar conservantes mediante atomización en salchichas con tripas de celulosa.

- Determinar el mejor conservante en base al tiempo de vida útil del producto.

- Determinar la carga microbiana existente a los 15, 30 y 45 días después de la aplicación del conservante en el producto.

- Evaluar las características organolépticas de las salchichas con tripa de celulosa tratada con los conservantes.

Los procesos de elaboración de salchichas están definidos, y los problemas de las industrias permiten realizar investigaciones con supuestos a comprobarse en ese caso:

- $\mathrm{H}_{0}$ : La aplicación de conservantes por atomización no influirá en la calidad de la salchicha vienesa con tripa de celulosa.

- $\mathrm{H}_{1}$ : La aplicación de conservantes por atomización influirá en la calidad de la salchicha vienesa con tripa de celulosa.

\section{Metodología}

1. Localización y duración del experimento

El trabajo experimental se realizó en el Laboratorio de Cárnicos de la Facultad de Ciencias Pecuarias de la Escuela Superior Politécnica de Chimborazo, situada en la Panamericana Sur Kilómetro 11/2 vía a Guayaquil, a una altitud de $2740 \mathrm{msnm}, 78^{\circ} 4^{\prime}$ de Longitud Oeste y $1^{\circ} 38^{\prime}$ de Latitud Sur. 
Tuvo una duración de 60 días, distribuidos en la producción, aplicación y evaluación de los conservantes en el producto terminado. La unidad experimental fue de $3 \mathrm{~kg}$ de salchicha por cada uno de los tratamientos, los cuales posteriormente se empacaron al vacío en presentación de $300 \mathrm{~g}$.

\section{Materiales, equipos e instalaciones}

Para el desarrollo del trabajo experimental se utilizaron los materiales, equipos e instalaciones que se detallan a continuación:

- Materias primas: Carne de res, carne de cerdo, grasa de cerdo (lomo), hielo, fosfato, heritorbato, saborizante a salchicha Vienesa, sal, nittito, humo liquido, leche en polvo, fécula de papa, azúcar.

- Conservantes: Natamicina, propianato de sodio, sorbato de potasio.

- Materiales en la planta: Cuchillo, fundas para empacar al vacío, marcador, agua destilada, boras, mandil, cofia, jabón, desinfectantes, atomizador, varillas, carrito hornero, bandejas.

- Materiales de laboratorio: Espátula, papel aluminio, tubos de ensayo, vasos de precipitación, pipetas, peras de succión, placas $3 \mathrm{M}^{\mathrm{TM}}$ Petrifilm ${ }^{\mathrm{TM}}$ para recuento de mohos y levaduras, Agar M.R.S, cajas Petri, cuaderno de apuntes.

- Equipos en planta: Balanza electrónica, báscula de capacidad de 100 $\mathrm{kg}$ y una precisión de $5 \mathrm{gr}$, molino de carne, cutter, embutidora, horno ahumador, empacadora al vacío, congelador.

- Equipos de laboratorio: Balanza analítica, autoclave, cámara de flujo laminar, estufa bacteriológica, computadora portátil, cámara fotográfica, mechero Bunsen, licuadora, microscopio.

\section{Tratamiento y diseño experimental}

Se evaluó la salchicha con tripa de celulosa aplicando los distintos conservantes mediante atomización, empleados como bactericidas y fungicidas, para ser comparada con las salchichas obtenidas sin la aplicación de ningún conservante, como tratamiento control, por lo que se contó con cuatro tratamientos experimentales con tres repeticiones en ensayos consecutivos. Las unidades experimentales se distribuyeron bajo un diseño completamente al azar y se ajustaron al siguiente modelo lineal aditivo:

Donde:

$$
\mathrm{Y}_{\mathrm{ij}}=\mu+\mathrm{T}_{\mathrm{i}}+\varepsilon_{\mathrm{ij}}
$$

$Y_{i j:}$ : Valor estimado de la variable

$\mu$ : Media General

$T_{i}$ : Efecto de los niveles de conservantes

$\varepsilon_{i j}$ : Error Experimental

Se realizó un tratamiento por conservantes (Sorbato de Potasio, Natamicina, Propianato de Sodio) más el tratamiento testigo con un total de cuatro 
tratamientos, cada uno con tres repeticiones para el estudio del caso. El tamaño de la unidad experimental (T.U.E) fue de 3 kilogramos de salchicha con tripa de celulosa por cada tratamiento. De acuerdo a lo descrito anteriormente el esquema del experimento empleado se describe a continuación en la Tabla 1.

Tabla 1. Esquema del experimento. El tamaño de la unidad experimental (T.U.E.) fue de 3 kilos de salchicha con tripa de celulosa por cada tratamiento.

\begin{tabular}{|l|c|c|c|c|}
\hline Tratamientos & Código & Repeticiones & T.U.E.* & REP/TRATAM. \\
Testigo & T0 & 3 & $3 \mathrm{Kg}$ & $9 \mathrm{Kg}$ \\
Sorbato de potasio & T1 & 3 & $3 \mathrm{Kg}$ & $9 \mathrm{Kg}$ \\
Natamicina & T2 & 3 & $3 \mathrm{Kg}$ & $9 \mathrm{Kg}$ \\
Propianato de sodio & T3 & 3 & $3 \mathrm{~kg}$ & $9 \mathrm{Kg}$ \\
Total & & & $36 \mathrm{~g}$ \\
\hline
\end{tabular}

\section{Mediciones experimentales}

Las variables experimentales que se midieron en el producto terminado fueron las siguientes: (1) Análisis microbiológicos: Bacterias acido lácticas UFC/g. mohos y levaduras UFC/g. (2) Análisis organolépticos: Apariencia, color, sabor, textura, (3) Análisis estadístico y prueba de significancia: Análisis de varianza para las diferencias (ADEVA) para los datos microbiológicos, separación de medias de acuerdo a la prueba de Tukey al nivel de significancia de $\mathrm{P}<0.05$ y análisis con prueba no paramétrica de Kruskal Wallis en los datos organolépticos.

\section{Procedimiento experimental}

Aplicación de los conservantes por automatización. Cada conservante se disolvió en las cantidades máximas recomendadas por el fabricante en un litro de agua destilada según correspondía al tratamiento. Una vez enfriadas las salchichas en las duchas de enfriamiento estas se dejaron reposar aproximadamente 10 minutos para que se escurrir el exceso de agua y que de esta forma se seque la parte externa. Se procedió luego a atomizar el conservante sobre la superficie del producto terminado; esto se realiza con el propósito de que se permeabilicen los conservantes y formen una capa para la acción preventiva bactericida y fúngica. Véase en la Tabla 2.

Tabla 2. Cantidades usadas en 1 litro de agua destilada (Trujillo, 2016).

\begin{tabular}{|l|c|}
\hline \multicolumn{1}{|c|}{ Conservante } & gr/lt de agua \\
\hline Sorbato de potasio & 0,6 \\
Natamicina & 0,001 \\
Propianato de sodio & 3,2 \\
\hline
\end{tabular}




\section{Resultados y Discusiones}

1. Evaluación microbiológica de las salchichas con tripa de celulosa con la utilización de natamicina, sorbato de potasio, propianato de sodio como conservantes mediante atomización.

La concentración utilizada de los distintos conservantes fue de 0,001 $\mathrm{g} / \mathrm{L}$ de agua de Natamicina, $0,6 \mathrm{~g} / \mathrm{l}$ de agua de Sorbato de potasio y finalmente de 3,2 g/l de agua de Propianato de sodio.

Una vez terminado el proceso de elaboración se procedió a enfriar las salchichas con duchas de agua fría, y posteriormente se aplicaron los conservantes por cada tratamiento con 3 repeticiones más el testigo.

El análisis microbiológico de bacterias acido lácticas se realizó en el medio de agar MRS y los análisis para mohos y levaduras en Placas $3 \mathrm{M}^{\mathrm{TM}}$ Petrifilm ${ }^{\mathrm{TM}}$ para recuento de mohos y levaduras. Los valores obtenidos para bacterias ácido lácticas, mohos y levaduras en las salchichas con tripa de celulosa, en las cuales se utilizaron conservantes mediante atomización, fueron analizados mediante prueba estadística ADEVA con separación de medias mediante la prueba de Tukey. Dichos valores se presentan a continuación en la Tabla 3.

Los resultados de los recuentos microbiológicos se consideran como UFC/g a cada período de tiempo. Estos recuentosindican que los mejores resultados son una media de 6,67 de bacterias ácido lácticas con el tratamiento de Sorbato de potasio a los 15 días, una media de 101,67 de bacterias ácido lácticas a los 30 días y una media de 183,33 con el tratamiento de Natamicina, teniendo en cuenta que con este tratamiento se obtuvo menor crecimiento de bacterias ácido lácticas al final de la investigación a los 45 días. Véase la Tabla 3.

Tabla 3. Resumen microbiológico (Trujillo, G. et al., 2018).

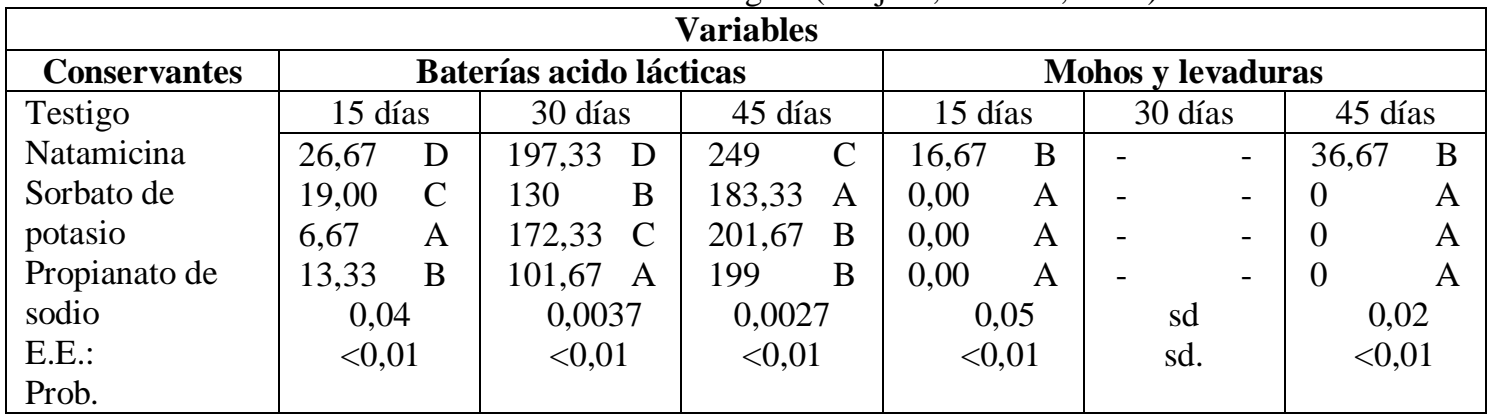

E.E.: Error Estándar. Prob. >0,05: no existen diferencias estadísticas. Prob. <0,05: existen diferencias estadísticas. Prob. $<0,01$ : existen diferencias altamente significativas. Medias con letras iguales en una misma fila no difieren estadísticamente de acuerdo a la prueba de Tukey

Los resultados en cuanto al crecimiento de bacterias ácido Lácticas en este tipo de producto cárnico no sobrepasan con ningún tratamiento el valor de $10^{7}$, considerado como referencia en las investigaciones anteriores a este 
trabajo, guardando relación con los datos obtenidos en el año 1999 por los investigadores Cayré, M. et al. quienes estudiaron el efecto de la proliferación de bacterias lácticas sobre la calidad de las salchichas tipo viena obteniendo que el crecimiento de bacterias ácido lácticas alcanza niveles superiores a $10^{7}$, a los 45 días. Al alcanzareste número se pudo observar la formación de limo sobre su superficie, la acumulación de exudado de color blanquecino y la pérdida de vacío de algunas muestras, y que el crecimiento es de forma exponencial con el tiempo.

El cuadro resumen indica las medias de los resultados obtenidos en relación a UFC/g de bacterias ácido lácticas en salchichas con tripa de celulosa, en cuatro tratamientos (testigo, Natamicina, Sorbato de potasio, Propianato de sodio) tomando datos en 3 períodos de tiempo (15, 30 y 45 días), registrándose a los 15 días diferencias significativas con los 4 tratamientos. El tratamiento con Sorbato de potasio reportó los mejores resultados en este tiempo con una media de 6,67; el tratamiento testigo (ningún conservante) presentó el mayor número de crecimiento bacteriano con una media 26,67, mientras que el tratamiento con Natamicina con 19,00 y de Sorbato de potasio con 13,33 presentaron diferencias estadísticas pero están enmarcados dentro del mejor y peor tratamiento.

Los datos obtenidos a los 30 días muestran que el mejor tratamiento luego de este período de tiempo es aquel con Propianato de sodio con una media de 101,67; se mantiene el mayor crecimiento bacteriano con el tratamiento testigo el cual muestra una media de 197,33. El tratamiento con Natamicina muestra una media de 130 siendo el segundo mejor tratamiento y el tratamiento con Sorbato de potasio se ubica en tercer lugar con una media de 172,33 .

En la toma final de resultados a los 45 días se observa que el tratamiento con Natamicina presenta el menor crecimiento bacteriano con una media de 183,33; los tratamientos con Propianato de sodio y Sorbato de potasio no presentan diferencias estadísticas pero si numéricas, y se mantiene un mayor crecimiento bacteriano con el tratamiento testigo con una media de 249 .

Con respecto al crecimiento de mohos y levaduras en salchichas con tripa de celulosa se observó que no hubo crecimiento de ningún tipo con los tratamientos de Natamicina, Sorbato de potasio y Propianato de sodio, más sin embargo hubo un ligero crecimiento en el tratamiento testigo con una media de 36,67 a los 45 días, en la investigación sobre la población microbiana asociada con salchichas tipo viena del año 1999 de los investigadores Cayré, M. et al. Se evidencia entonces una concordancia con la presente investigación, exponiéndose en las dos investigaciones que tanto mohos comolevaduras no superan las $50 \mathrm{UFC/g}$ y $1,3 \times 10^{2} \mathrm{UFC} / \mathrm{g}$ respectivamente.

Los resultados en cuanto al crecimiento de bacterias ácido lácticas en este tipo de producto cárnico no sobrepasan con ningún tratamiento el valor de 
$10^{7}$, considerando así que tienen acción preventiva y guardan la tendencia de los resultados obtenidos en el año 1999 por los investigadores Cayré, M. et al. quienes estudiaron el efecto de la proliferación de bacterias lácticas sobre la calidad de las salchichas tipo viena y demostraron que el crecimiento de bacterias ácido lácticas alcanza niveles superiores a $10^{7}$, a los 45 días. Luego de este número de días se pudo observar la formación de limo sobre su superficie, la acumulación de exudado de color blanquecino y la pérdida de vacío de algunas muestras.

Analizando los datos en el crecimiento de mohos y levaduras a los 15 días observamos que el mayor crecimiento con una media de 16,67 se da en el tratamiento testigo, mientras que los restantes tres tratamientos no presentan diferencias ni numéricas ni estadísticas teniendo una media de 0,0 .

A los 30 días el número de colonias presentes en las placas $3 \mathrm{M}^{\mathrm{TM}}$ Petrifilmpara recuento de mohos y levaduras, luego de aplicar los métodos estadísticos de ADEVA y la separación de medias de Tukey, no mostró diferencias significativas en el crecimiento de mohos y levaduras en ninguno de los 4 tratamientos.

En la toma final de datos a los 45 días se observa que el mayor crecimiento de mohos y levaduras se da en el tratamiento testigo con una media de 36,67 mientras que los restantes tres tratamientos no presentan diferencias ni numéricas ni estadísticas teniendo una media 0,0 .

\section{Bacterias ácido lácticas}

La figura 1 permite visualizar el comportamiento del crecimiento microbiano con los diferentes tratamientos en los tres tiempos estipulados (15, 30 y 45 días). Al final del tiempo estipulado en este experimento (45 días) es evidente que el tratamiento con mejores resultados al existir menor crecimiento bacteriano (bacterias ácido lácticas) es el producido con el conservante Natamicina. Con los tratamientos con Propianato de sodio y Sorbato de potasio existe un crecimiento igual de bacterias ácido lácticas, mientras que el tratamiento testigo mantiene el mayor crecimiento de bacterias ácido lácticas. 


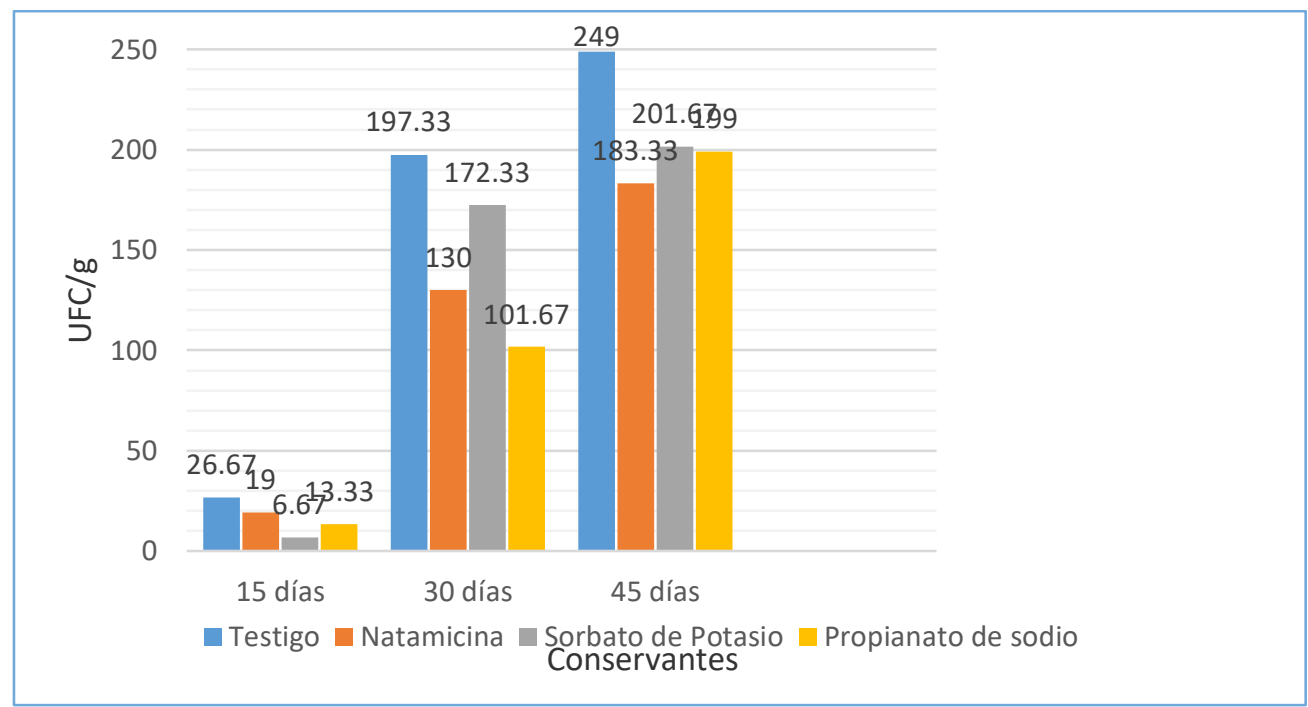

Figura 1. UFC/gr de bacterias ácido lácticas en las salchichas con tripa de celulosa con la utilización de conservantes durante 15, 30 y 45 días (Trujillo, G. et al., 2018).

\section{Mohos y levaduras}

Suponiendo que no existe crecimiento de mohos y levaduras durante los 45 días de la investigación, con respecto al tratamiento se observa que hubo un crecimiento leve con un valor medio de 2,6. En este sentido, la figura 2 indica el comportamiento del crecimiento de mohos y levaduras con los diferentes tratamientos en los tres tiempos estipulados (15, 30 y 45 días).

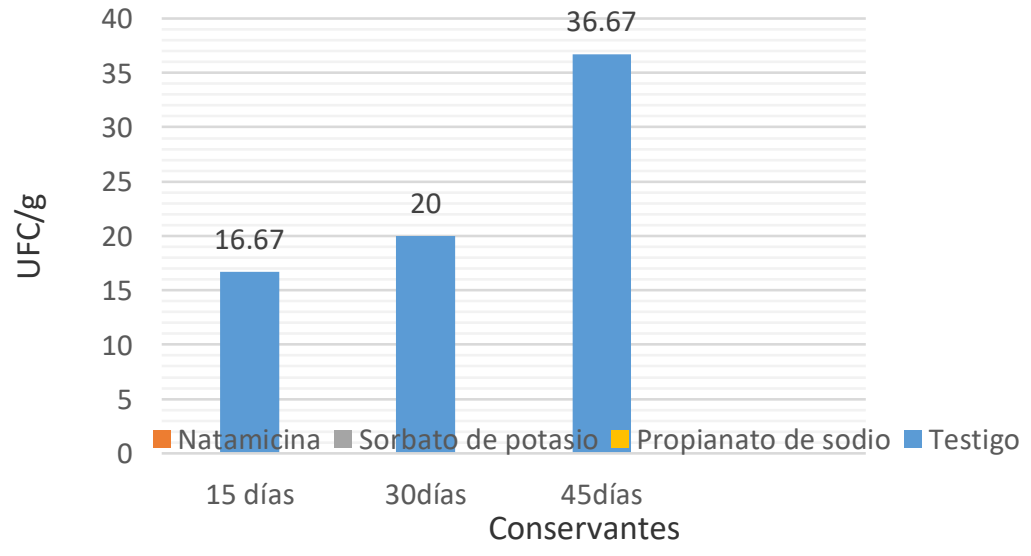

Figura 2. UFC/g de Mohos y levaduras en las salchichas con tripa de celulosa con la utilización de conservantes durante 15, 30 y 45 días (Trujillo, G. et al., 2018). 
4. Evaluación organoléptica de las salchichas con tripa de celulosa con la utilización de natamicina, sorbato de potasio, propianato de sodio como conservantes mediante atomización.

Las pruebas organolépticas se realizan con aplicación de los sentidos olfativos, visuales, táctiles, gustativos. Las medias obtenidas del análisis sensorial son dadas por la prueba estadística de Kruskal Wallis que se tabulan en la Tabla 4.

Tabla 4.Resumen análisis sensorial (Trujillo, G. et al., 2018).

\begin{tabular}{|l|c|c|c|c|}
\hline $\begin{array}{c}\text { Parámetros } \\
\text { organolépticos }\end{array}$ & $\begin{array}{c}\text { Testigo } \\
(\mathbf{6 2 3 9})\end{array}$ & $\begin{array}{c}\text { Natamicina } \\
\mathbf{( 8 7 2 1 )}\end{array}$ & $\begin{array}{c}\text { Sorbato de } \\
\text { Potasio } \\
\mathbf{( 4 6 2 6 )}\end{array}$ & $\begin{array}{c}\text { Propianata de } \\
\text { Sodio } \\
\mathbf{( 3 9 6 6 )}\end{array}$ \\
\hline Apariencia & 3,93 & 4,19 & 4,07 & 4,19 \\
Color & 4,29 & 4,30 & 4,17 & 4,15 \\
Sabor & 4,36 & 4,20 & 4,22 & 4,24 \\
Textura & 4,50 & 4,65 & 4,42 & 4,61 \\
H. & 3,60 & 4,53 & 0,91 & 3,63 \\
P. & 0,247 & 0,1904 & 0,8174 & 0,2982 \\
\hline
\end{tabular}

Prob. >0,05: no existen diferencias estadísticas. Prob. <0,05: existen diferencias estadísticas. Prob. $<0,01$ : existen diferencias altamente significativas.

\section{a. Color}

El color de las salchichas se determinó por métodos visuales por un panel de 7 catadores semi entrenados con un test descriptivo. Estadísticamente fueron similares $(\mathrm{P}>0,05)$, por efecto que no se modificó la formulación sino que sólo se aplicaron los conservantes mediante atomización y los mismos son incoloros. La media más baja de 4,17 se obtuvo en el tratamiento de Sorbato de potasio y la más alta es de 4,30 con el tratamiento de Natamicina, observando que hay diferencias numéricas entre los tratamientos y que no existe una diferencia significativa en este parámetro. En la totalidad de los tratamientos se presenció una coloración rojo pálido debido a que la carne de cerdo es rosácea por su grasa interfibrilar, con poca presencia de mioglobina que es el principal pigmento del músculo (Lawrie, 2007), por lo que el color que presenta la salchicha pudo deberse a la utilización de los nitritos que acentúan una mejor pigmentación. Véase en la Figura 3. 


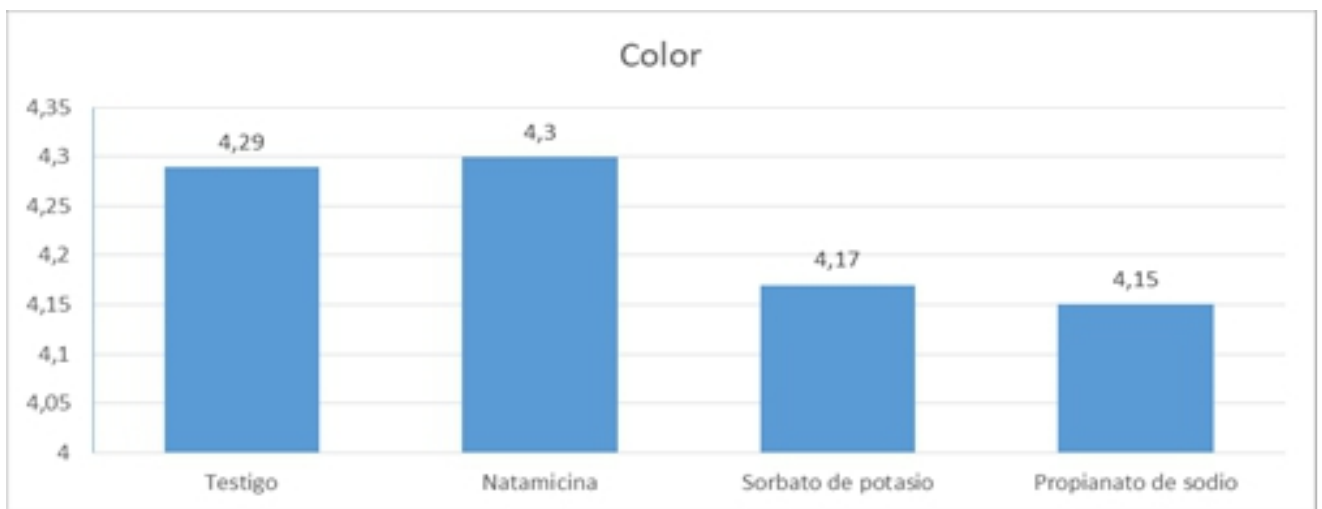

Figura 3. Color en salchichas con tripas de celulosa utilizando conservantes mediante atomización (Trujillo, G. et al., 2018).

\section{b. Apariencia}

Con respecto a la apariencia visual la misma fue uniforme sin marcas, sin presentarse ninguna diferencia que resalte entre todos los tratamientos. La mejor media en apariencia fue el tratamiento de Natamicina y Propianato de sodio con una media 4,19 y la menor media fue la del tratamiento testigo con una media de 3,93. Cabe recalcar que en ningún tratamiento se notó ninguna alteración principalmente de limo durante los 45 días correspondientes al tiempo de la presente investigación. Véase en la Figura 4.

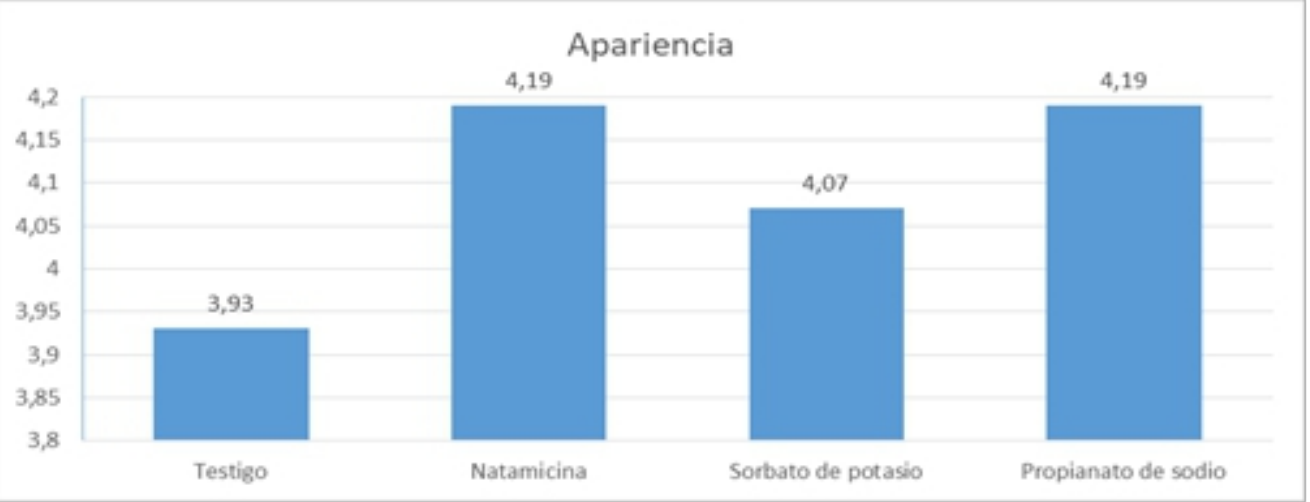

Figura 4. Apariencia en salchichas con tripas de celulosa utilizando conservantes mediante atomización (Trujillo, G. et al., 2018).

\section{c. Sabor}

Los valores medios obtenidos en cuanto al sabor a través del sentido del gusto expresan que la media más alta es aquella del tratamiento testigo con 4,36 y la más baja es de 4,10 en el tratamiento con Natamicina. La aplicación de los conservantes no influenció en el sabor ya que estos fueron aplicados por atomización sobre la salchicha terminada. Cabe destacar que los conservantes no tienen sabor por tal razón no aportaron ningún sabor extraño a la salchicha terminada. Véase en la Figura 5. 


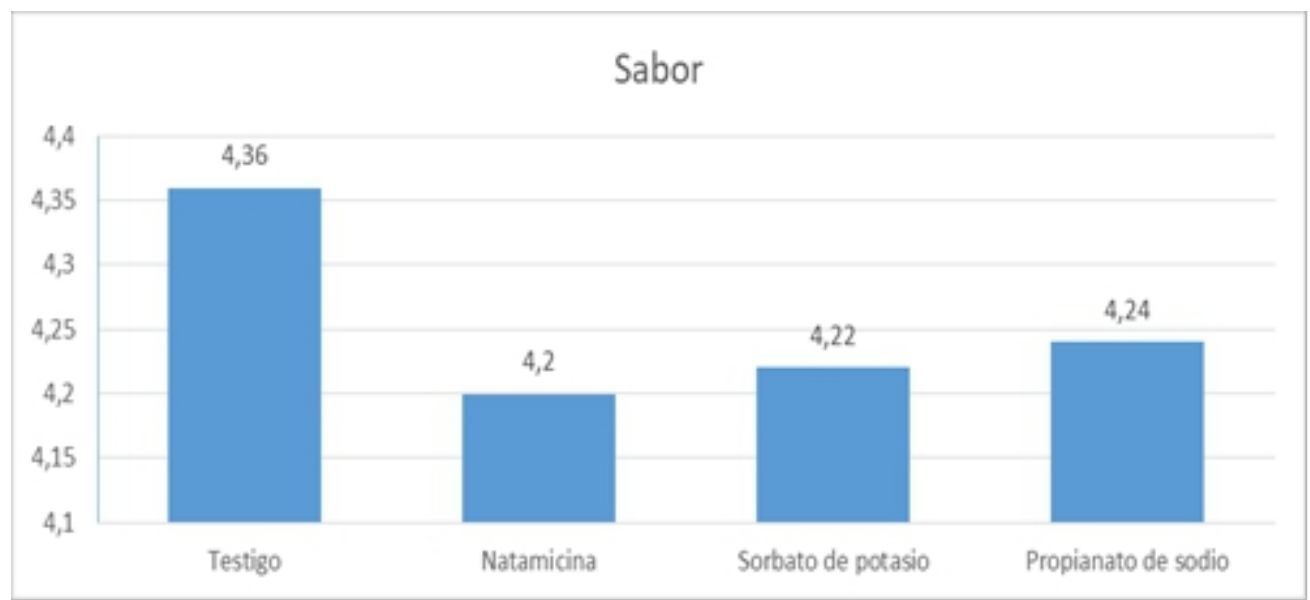

Figura 5. Apariencia de las salchichas con tripas de celulosa utilizando conservantes mediante atomización (Trujillo, G. et al., 2018).

\section{d. Textura}

La textura se determina mediante el sentido del tacto por los dedos y la mordida. En la valoración de las medias en la característica de textura no se presentaron diferencias estadísticas, sólo numéricas. Dichas diferencias indican que las salchichas fueron aceptadas por el consumidor, teniendo la mejor media el tratamiento con Natamicina con una media de 4,65 mientras que la más baja es de 4,42 correspondiente al tratamiento con Sorbato de potasio. Véase en la Figura 6.

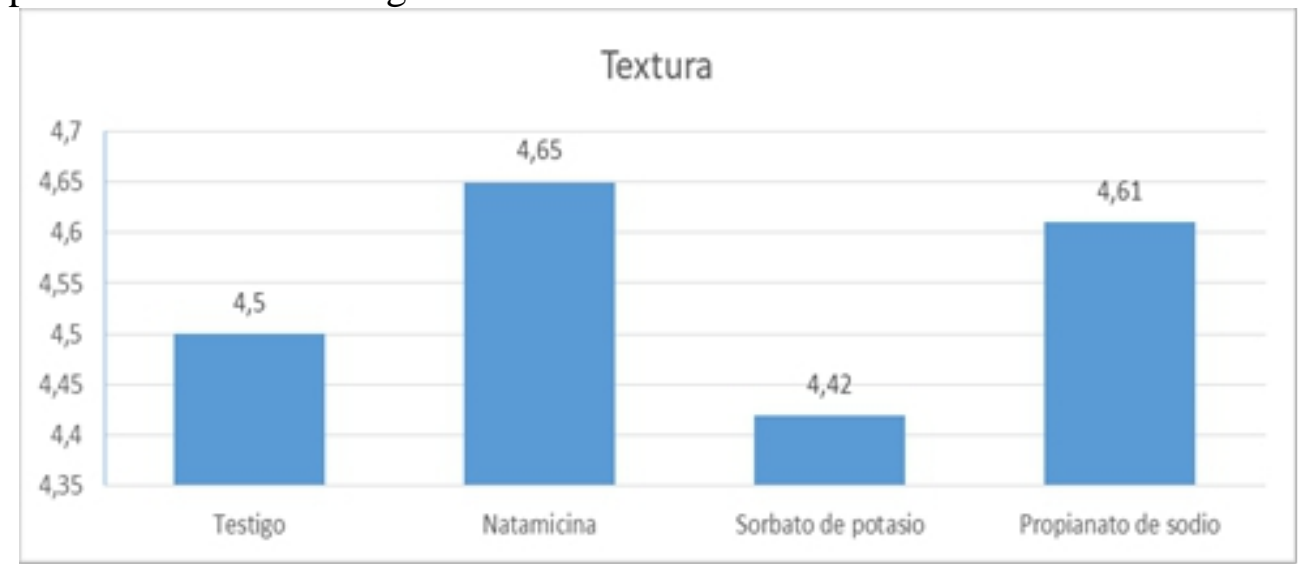

Figura 6. Textura en salchichas con tripas de celulosa utilizando conservantes mediante atomización (Trujillo, G. et al., 2018).

\section{Conclusiones}

Tomando en cuenta lo expuesto anteriormente es posible afirmar que es necesario utilizar conservantes en concentraciones determinadas de $\mathrm{g} / \mathrm{L}$, atomizar una vez que estén frías las salchichas y realizar las observaciones en los tiempos establecidos. Las características organolépticas son similares y las 
microbiológicas con presencia de menores medias fueron con el tratamiento con Natamicina, por lo cual la hipótesis alternativa es positiva.

A partir de los análisis realizados se encontró que el tratamiento testigo ( sin conservantes) permite ver las diferencias de los resultados por atomización de conservantes, siendo la Natamicina la que mejores resultados tantos microbiológicos y organolépticos presenta.

Se determinó igualmente que el mejor conservante en base al tiempo de vida útil del producto fue el conservante Natamicina, el cual que presentó una media de $183,33 \mathrm{UFC} / g$ de bacterias ácido lácticas y una media de 0,0 UFC/g de mohos y levaduras. Pasados los cuarenta y cinco días de haberse aplicado este tratamiento en las salchichas con tripa de celulosa, no se presentó ninguna alteración (limo, líquido blanquecino u otros) con respecto a color, textura, sabor, apariencia.

Los valores de las medias estadísticas indican que a los quince días el mejor tratamiento fue el de Sorbato de potasio, a los treinta el Propianato de sodio, y a los cuarenta y cinco el de Natamicina. Con respecto a la formación de mohos y levaduras los conservantes no presentaron UFC/g.

En la evaluación de las características organolépticas de las salchichas con tripa de celulosa tratadas por atomización con los conservantes se observan valores de medias superiores a 3,9 que agradaron a los consumidores, por ende el uso de dichos conservantes no influyen en las mismas.

\section{References:}

1. Amerling, C. (2001). Tecnología de la Carne. EUMED, 7 - 8. Obtenido de http://publicacionescbs.izt.uam.mx/DOCS/carnes.pdf

2. Aersa (2017). Tripas. Abastecedora de Empacadoras y Rastros S.A de C.V. Obtenido de http://www.aersa.net/consumibles/tripas/

3. Barros, C. (2009). Los aditivos en la alimentación de los españokes y la legislación que regula su autorización y uso. Madrid, España: Vision Libros.

4. Barioglio, C., Varela, L., Rubiales, S., \& Deza, M. (2013). Diccionario de producción animal. Córdoba, Argentina. Editorial Brujas, pp 264.

5. Blandino, L. (2005). La Industria de la Carne Bovina en Centro América: Situación y Perspectivas. Alajuela, Costa Rica: Grafica Litho Offset, S.A, pp 40-42.

6. Bedolla, S et al. (2004). Introducción a la Tecnología de Alimentos. 2da ed. México D.F, México. Editorial Limusa, S.A, pp 67, 83.

7. Blogspot (2008). Propianato de sodio. Disponible en: http://propianatode-sodio.blogspot.com/.

8. Cayre, M. (1999). Efecto de la Proliferación de Bacterias Lácticas Sobre la Calidad de las Salchichas tipo Vienesa. Disponible en: http://www.unne.edu.ar/unnevieja/Web/cyt/cyt/exactas/e-039.pdf 
9. Cayre, M. (1999). Población Microbiana Asociadas con Salchichas Tipo

Vienesa.Disponibleen:http://www.unne.edu.ar/unnevieja/Web/cyt/cyt/ exactas/e-040.pdf

10. Castro, K. (2011). Tecnología de alimentos. Bogotá, Colombia. Ediciones de la U, pp 39-42.

11. Control Microbiológico De Alimentos. Departamento De Química (2013). uía de trabajos prácticos. Disponible en: http://www.qo.fcen.uba.ar/quimor/wpcontent/uploads/2013/09/GUIA-TP-CONTROL-2013.pdf

12. Cuador Instituto Ecuatoriano De Normalización Inen (2013). Carne Y Productos Cárnicos. Definición. Nte Inen 1217:2013. Disponible en: http://normaspdf.inen.gob.ec/pdf/nte_2015/07/nte-inen-1217-2.pdf

13. De Oña, C., Serrano, D., \& Orts, M. (2012). Elaboración de preparados cárnicos frescos: carnicería y elaboración de productos cárnicos. (MFO297_2). Málaga, España. IC Editorial, pp 61.

14. Delves, J et al. (2005). Antimicrobianos en los alimentos. 3ra ed. Boston, Estados Unidos de Norteamerica. Taylor\&Francis, pp 275.

15. Dorado, E. (2011). Acondicionamiento de la carne para su comercialización. Málaga, España. Innova, pp 24, 25.

16. Ecuador Instituto Ecuatoriano De Normalización Inen (2012). Carne Y Productos Cárnicos. Clasificación De La Carne Vacuna Nte Inen 775:1985. Disponible en: http://normaspdf.inen.gob.ec/pdf/nte/775C.pdf

17. Ecuador Instituto Ecuatoriano De Normalización Inen (2012). Carne Y Productos Cárnicos. Muestreo. Nte Inen 776:2012. Disponible en: http://www.normalizacion.gob.ec/wpcontent/uploads/downloads/2013 /11/nte_inen_776.pdf

18. Ecuador Instituto Ecuatoriano De Normalización Inen (2013). Control Microbiológico De Los Alimentos. Mohos Y Levaduras Viables. Recuentos En Placa Por Siembra En Profundidad Nte Inen 152910:2013.

Disponible en:http://www.normalizacion.gob.ec/wpcontent/uploads/downloads/2 014/NORMAS_2014/ACO/17122014/nte-inen-1529-10-1r.pdf

19. Flores, I. (2001). Manual de Técnicas de laboratorio para la Industria. AASI, Riobamba, pp. 24, 40.

20. Gil, A., Ruiz, L., \& Dolores, M. (2010). Composición y Calidad Nutritiva De Los Alimentos. 2da ed, Madrid: Medica Panamericana S.A, pp. 46,47

21. Ingeniería y desarrollo alimentario, S.A. de C.V. 2012. Sorbato de potasio. 
Disponibleen:www.idealsa.com/literaturas/Sorbato\%20de $\% 20 \mathrm{~K} \% 20$ LIT.doc

22. Hleap, J., Burbano, M., \& Mora, J. (2017). Evaluación fisicoquímica y sensorial de salchichas con inclusión de harina de quinua (Chenopodium quinoa $\quad$ W.). Scielo, 5. doi: doi://dx.doi.org/10.18684/bsaa.

23. Jinpeng (2014). Aditivos Alimentarios: E235 Natamicina (Pimaricina). Obtenido de alimentarios.com/2016/01/E235.html https://www.aditivos-

24. Jinpeng (2014). Aditivos Alimentarios: E281 Propianato de Sodio. Obtenido de http://www.aditivos-alimentarios.com/2014/01/e281propianato-sodio.html

25. King, B et al. (2003). Food dditives other than colour and sweeteners, as amended. AIB Tachnical Bulletin. Bradford, Reino Unido pp 8- 12.

26. Mäkelä, $P$ et al. (1992) Classification of ropy slime-producing lactic acid bacteria based on DNA-DNA homology, and identification of Lactobacillus sake and Leuconostoc amelibiosum as dominant spoilage organisms in meat products. J. Food Microbiol. (13) pp 167- 172.

27. Mira, J. (1998). Compendio de ciencia y tecnología de la carne. Riobamba, Ecuador. AASI, pp 140, 141.

28. Oleas, M et al. (2012). Aspectos bromatológicos de conservantes y colorantes: Toxicología alimentaria. Madrid, España. Díaz de Santos pp 473.

29. Organización De Las Naciones Unidas Para La Alimentación Fao (2014).

Disponibleen:http://www.fao.org/ag/againfo/themes/es/meat/backgro und.html

30. Quinet (2000). Conozca las capacidades conservantes del potasio. Disponible en:http://www.quiminet.com/articulos/conozca-lascapacidades-conservantes-del-sorbato-de-potasio-2814300.htm

31. Quezada, A. (2015). Estudio Bromatológico Y Microbiológico De Vienesa, Utilizando Diferentes Formulaciones De Extracto De Pimiento Rojo (Capsicum annuum). Obtenido de Universidad Nacional de

Loja:

http://dspace.unl.edu.ec/jspui/bitstream/123456789/11448/1/TESIS\% 20ADRIANA\%20GISSELA\%20QUEZADA\%20SALAS.pdf.

32. Rodriguez, M. (2004). Técnicas de embutición, embuchado y enmoldado de masa y piezas cárnicas: practica para la elaboración de productos cárnicos. Vigo, España. Ideas propias editorial S.L, pp 4,5.

33. Rodríguez, V. (2008). Bases de la alimentación humana. La Coruña: Netbiblo, S.L, pp. 87. 
34. Tovar, A. (2003). Guía de procesos para la elaboración de productos cárnicos. Bogotá, Colombia. CAB, pp 31.

35. Vargas, C., López , A., \& Flores , L. (2014). Evaluación de la concentración de nitratos / nitritos y cloruro de sodio en embutidos expendidos en la cuidad de Tarija. Scielo, 1(7). Obtenido de http://www.revistasbolivianas.org.bo/scielo.php?pid=S230560102014 $000100002 \&$ script $=$ sci_arttext

36. Wittig, E. (2001). Evaluación Sensorial Una metodología actual para tecnología de alimentos. Disponible en: http://mazinger.sisib.uchile.cl/repositorio/lb/ciencias_quimicas_y_far maceuticas/wittinge01/ 